\title{
Publishing without (some) belief
}

\author{
Will Fleisher
}

Pre-print version, forthcoming in Thought: A Journal of Philosophy. https://doi.org/10.1002/tht3.466

\begin{abstract}
Alexandra Plakias has recently argued that philosophers may permissibly publish claims they do not believe. This raises the question: when is it permissible to publish without belief? Is it always? I provide three counterexamples to the idea that it is always permissible to publish without belief. I argue that it is only permissible to publish a certain kind of claim when one does not believe it. I call these advocacy role claims. Another kind of claim is impermissible to publish without belief: what I call evidential role claims. These types are distinguished by their function. Advocacy role claims aim to promote productive debate and disagreement. Evidential role claims aim to add to the common stock of evidence. The resulting theory incorporating the distinction explains the differences between Plakias' cases and mine. It is applicable to publishing in a wide variety of fields beyond philosophy.
\end{abstract}

Philosophers have recently been interested in the appropriate attitude to have toward a controversial philosophical theory. There are a variety of reasons to doubt that belief is appropriate, as the high epistemic standards required for justified belief would seem to exclude too many philosophical theories as viable options. Relatedly, there are worries about assertions of philosophical claims, since assertion is also thought to be governed by substantive epistemic norms. In light of this, a variety of alternative attitudes have been proposed in order to characterize philosophical commitment and assertion. ${ }^{1}$

Alexandra Plakias (2019) has helpfully expanded this discussion to the topic of philosophical publication. Plakias argues that it is permissible for philosophers to write and publish works (e.g., journal articles or books) that include claims they do not believe, a practice she calls publishing without belief (PWB). ${ }^{2}$ Her thesis is carefully limited to philosophy, as opposed to

\footnotetext{
${ }^{1}$ For the reasons to worry about the appropriateness of belief, see Frances $(2010,2013)$, Goldberg (2013). For proposed alternative attitudes, see Barnett (2019), Carter (2018), Goldberg (2015), McKaughan (2007), Palmira (2019), and Fleisher (2018). For accounts of philosophical assertion, see Goldberg (2015) and Fleisher (2019).

${ }^{2}$ I will talk in terms of 'claims' in order to remain neutral about which types of speech acts publishing involves. On this usage, claims are token speech acts: statements uttered in writing.
} 
publishing in other fields. Plakias' appeals to three helpful cases to provide a compelling argument that PWB is sometimes permissible. However, this raises further questions: just when is PWB permissible? Is it universally or even generally permissible?

I argue that only claims of a certain kind are permissible to publish without belief. The picture I propose recognizes two roles for claims made in published works: what I will call the advocacy and evidential roles. Advocacy claims should often be published despite authors' lack of belief in them. Evidential role claims, however, require a higher epistemic standing, one that does include a belief requirement. On this theory, Plakias' cases are permissible examples of PWB because they involve advocacy role claims. I will offer another three cases illustrating that it is impermissible to publish evidential role claims without belief. The resulting account of the norms of publishing is applicable to research areas beyond just philosophy.

\section{Publishing without belief}

Plakias provides three helpful cases to motivate her argument that PWB is permissible $(2019,1$; slightly paraphrased):

Malicious Deceiver: Ben submits a paper to a journal arguing for a view he considers patently absurd. His intent is to expose the journal's lax editorial standards. Only a fool, he thinks, would endorse his conclusions or be persuaded by his arguments. The paper is ultimately published.

Repentant (non) Realist: Sanjay is unconvinced of moral nonnaturalism. He finds it implausible. However, he has a compelling response to many of the central objections to it. He publishes them under the title 'A defence of nonnaturalism'. He continues to believe nonnaturalism is false; nowhere in the paper does he say this.

Doubtful Graduate: Rachel is a graduate student whose dissertation contains an argument against an increasingly popular position. But she's not confident the position she's critiquing is wrong-she suspects it might be correct. Furthermore, her critique relies on empirical research that she fears will turn out to be false. Nonetheless she has an original argument; she publishes it.

The first case is inspired by a recent actual "hoax," while the other two cases seem both possible and plausible.

Plakias suggests that, in each of the above cases, the philosopher in question has not erred or acted inappropriately. Despite their lack of belief in their published claims, they have not violated any epistemic or philosophical

Following Plakias, I am treating publishing as a speech act of the author. One might also wonder about a publisher or editor's normative requirements, but that is not the topic here. 
norms in publishing them. She provides several lines of argument to support this intuitively plausible conclusion.

First, she canvasses a variety of accepted epistemic norms and argues that PWB does not violate them. For instance, Plakias claims, none of these philosophers publish things they know to be false. Nor do they knowingly attempt to convince readers of false claims. Thus, they are not lying. Even Ben is not trying to deceive the readers, she suggests, as he takes the claims to be too absurd to believe, and in any case will expose the hoax as soon as the article is successfully published. (However, I think the malicious deceiver case complicates things here. One might think that Ben knows his claims to be false and is indeed lying. This might be true, even if he is acting permissibly all-things-considered. However, the arguments I make in this paper won't require thinking that Ben is acting permissibly. I will return to these points below.)

Second, Plakias considers norms of publication that explicitly rule out PWB. She considers whether published claims in philosophy should be treated as typical assertions: governed by a knowledge, truth, or justified belief norm. ${ }^{3}$ However, such a norm would be violated by most publishing in philosophy, given the difficulty and disagreement to be found there. Moreover, any belief-requiring norm would lead to a variety of bad consequences. Such a norm could skew the literature by discouraging the publication of arguments for skeptical theories (e.g., conciliationism ${ }^{4}$ ). It would also deprive the literature of many interesting arguments that did not convince their authors. ${ }^{5}$

Third, Plakias argues anti-PWB norms would contribute to inappropriate deference. Junior philosophers would be less likely to contribute to debates, as they may feel pulled to defer to those with greater expertise. Plakias argues that this may disproportionately impact philosophers from underrepresented groups. Thus, making PWB impermissible deprives philosophy of potentially convincing arguments, and of input from important standpoints and perspectives. $^{6}$

These arguments are compelling and persuasive as applied to the three cases above. In each case, the philosopher makes claims they do not (and should not) believe. Nonetheless, their doing so is beneficial for philosophical inquiry. They are making important new arguments available, avoiding inappropriate deference, and perhaps even promoting diverse perspectives. Furthermore, I would add that they are contributing to an appropriate division of cognitive labor (Kitcher 1990, Strevens 2003), helping to avoid premature consensus (Zollman 2010), and being appropriately sensitive to

\footnotetext{
${ }^{3}$ See DeRose (2002), Williamson $(1996,2000)$ for the knowledge norm; Weiner (2005) for a truth norm; and Douven (2006), Kvanvig (2011), Lackey (2008) for justification/justified belief norms.

${ }^{4}$ For overviews of the literature on disagreement, see Christensen (2009), Frances (2014).

${ }^{5}$ DeRose (2016), Goldberg (2015) also recognize that high-standard norms of assertion cause difficulties in philosophy.

${ }^{6}$ See Plakias (2019) for additional considerations in favor of the permissibililty of PWB.
} 
considerations of collective inquiry (Fleisher 2018). For these reasons, I agree that Ben, Sanjay, and Rachel are acting epistemically and philosophically appropriately in publishing these claims.

\section{Publishing with belief}

Plakias' arguments establish that it is sometimes permissible for a philosopher to publish claims they do not believe. However, the question remains: just when is such PWB permissible?

In this section, I argue that it is not always permissible. The right account of epistemically appropriate publishing permits some kinds of PWB, but prohibits others. To support my argument, and to help illustrate the resulting account, I offer another three cases:

Fraudulent Deceiver: Chet submits a paper to a philosophy journal arguing for a view he considers patently absurd, in order to expose the journal's lax editorial standards. The argument includes premises based on fraudulent research that Chet has fabricated. The paper is subsequently published.

Negligent Experimenter: Linda is an experimental philosopher who runs an experiment surveying folk intuitions about moral realism. She intends to use Amazon's Mechanical Turk service, but accidentally signs up for a different service, Nile Physical Ottoman. Linda subsequently discovers her mistake, but due to time pressure she does not investigate whether NPO is a reliable service. She thus does not believe her results. However, she publishes an article based on the experiment anyway, where the results are treated as important premises in her argument.

Poorly-read Ethicist: Nelson writes an overview article about the state of the field in normative ethics for an online encyclopedia. Nelson has negligently only read a small portion of the papers he refers to in the article. Recognizing this negligence, he does not believe a number of the claims he makes about the arguments contained in various papers. He publishes the article anyway.

The first case is inspired by a real case of "hoax" paper submission. ${ }^{7}$ The other two cases are possible, and though perhaps no cases quite so egregious have occurred, they are illustrative of things that may have. In all three cases, the authors publish claims that they do not believe, and are in no position to rationally believe. Chet in fact knows that the claims he makes about his fraudulent research are false. Linda, meanwhile, knows she would not be justified in believing the results of her experiment (or even that the experiment was actually run). Similarly, Nelson knows he has not done

\footnotetext{
${ }^{7}$ This is inspired by Lindsay, Boghossian, and Pluckrose (2018). I take it this is the same hoax case Plakias refers to.
} 
adequate due diligence, so doesn't believe the claims he has made about other philosophers' papers.

Each of these cases involves publishing without belief. I think that each also involves epistemically and philosophically inappropriate behavior: Chet, Linda, and Nelson have each erred. Moreover, they have erred because they have published claims they do not believe. Here, they do not believe the claims precisely because doing so would be unjustified. Not only is this kind of PWB intuitively impermissible, it leads to bad consequences.

In negligent experimenter, Linda's claims are aimed at convincing her readers to believe them. She does not know her claims are false, though she knows they are unjustified. This is epistemically irresponsible and risks spreading falsehoods to other philosophers. A general practice of acting as Linda does would invariably lead to widespread false beliefs, or to a problematic undermining of trust among philosophers. Poorly-read ethicist illustrates a similar issue. The difference is that Nelson's claims are not about empirical research. Instead, they concern what Goldman (2001) calls secondary knowledge. These are claims about a field of research, rather than claims which answer the questions that are the primary focus of the field's research. ${ }^{8}$ This shows that the claims at issue are not limited to empirical research.

In fraudulent deceiver, Chet's actions will also lead to bad consequences, including that philosophers will believe false claims about empirical research (claims that Chet knows to be false). Chet is guilty of violating more general norms against deception, in particular, norms against making up research. Chet knowingly makes false claims in a bid to deceive the editors and reviewers of the journal about his empirical research. Moreover, the very claims he is deceiving them about will be published in the paper. This deception will then carry a risk that some readers will also believe that the research was undertaken. To readers, the results of empirical research seeming absurd is not always a good reason to discount them: science often surprises us.

This contrasts with Ben in Plakias' malicious deceiver case. Ben is providing an argument for claims he expects no reader to believe, as he (perhaps incorrectly) trusts the obvious absurdity of the claims to strain reader credulity. Moreover, it is reasonable to expect referees and editors to agree to publish claims like Ben's without believing the claims themselves. So Ben aims to convince no one of the false claims he publishes. He does need to deceive the editors and reviewers, but only about claims which will not actually be published. That is, he needs to deceive them about his motivations, and claims about his personal motivations won't be published.

\footnotetext{
${ }^{8}$ Not all claims about other philosophers will be secondary knowledge. Secondary knowledge claims are well-established and mostly uncontroversial claims that experts in a sub-field will be expected to know, e.g., "Goldman endorses process reliabilism." Contrast this with a controversial claim from the history of philosophy, e.g., "Kant's formulations of the categorical imperative are not equivalent." This would not count as secondary knowledge, as it concerns the subject of the inquiry and remains controversial.
} 
Chet, on the other hand, intends and expects the reviewers to believe his published claims about the empirical research. This offers a clear distinction between Ben and Chet, one that is relevant to evaluating them, even if neither acts permissibly. Ben does not knowingly publish false claims that there is much risk anyone will believe. Chet is knowingly publishing false claims that there is great risk will be believed.

Despite these differences, as noted above, malicious deceiver does seem more controversial than Plakias' other cases. Plakias' claim that Ben is neither lying nor telling known falsehoods depends on certain background commitments. The first is part of the traditional definition of lying: that intent to deceive about $P$ is required for someone to be lying about $P$. But on many contemporary views, lying does not require an intent to deceive (Mahon 2016). The second background commitment is that recognition of the patent absurdity of $P$ is inadequate to grant someone knowledge that $P$ is false. If this is right, Ben may still not know his claims are false. If one shares these commitments, then Plakias is right that Ben is neither lying nor publishing claims he knows to be false.

One might be skeptical of these commitments. However, even if one doubts them, this does not yet show that Ben is acting impermissibly, all-things-considered. After all, lying is sometimes permissible when it is done in a way that promotes important goals (e.g., protecting innocents from murderers at the door). Ben's hypothetical case may be such a time. In that case, his publishing still counts as permissible PWB. But even if Ben is acting impermissibly, his case is still usefully contrasted with fraudulent deceiver, for the reasons pointed out above. Chet is publishing claims that are more clearly impermissible, and are worse to publish, because of the significant risk he runs of causing others to believe falsehoods. Furthermore, Plakias' other cases are adequate to establish that PWB is sometimes permissible.

One might worry that it in each of my cases it is the author's lack of epistemic standing, and not their lack of belief, that explains why their publishing is impermissible. It is the fact that Linda and Nelson would be unjustified in believing that really explains why their behavior is inappropriate. I think there is something to this thought. For instance, if Nelson had actually read and understood each paper he cites, thus putting him in a position to justifiably believe his claims, his actions would look significantly less bad. Still, I think it is clear that he is making a mistake even if he does this. It is his epistemic duty as an author to carefully consider whether what he is claiming is true, and to work to ensure that it is. Doing this will require him to consider his evidence and whether it adequately supports the truth of his claims. Here, the kind of adequacy required means that the evidence is sufficient to justify his attempt to get others to believe the claims. If he is proceeding as he ought, this should lead him to form a justified belief on the matter. Failing to do so renders the publishing of his claims epistemically impermissible.

These three new cases thus illustrate the bad consequences of a certain kind of PWB. When an author publishes a claim with the aim of having their 
audience believe it on trust, they are required to (justifiably) believe that claim. Failure to meet this standard will lead to a proliferation of falsehood. Moreover, it can undermine an important and valuable kind of deference: trusting the testimony of other philosophers. Importantly, as Plakias' cases show, not all claims made by philosophers are meant as this kind of testimony. We thus need to distinguish which claims are meant to play this testimonial role, and which are meant to play another role.

\section{Two roles for published claims}

As I have suggested, we should distinguish between the kind of PWB in Plakias' cases (by Ben, Sanjay, and Rachel) and the kind found in my cases (by Chet, Linda, and Nelson). Moreover, this distinction is already implicitly respected by our philosophical practice. If Chet, Linda, or Nelson subsequently make public their poor epistemic standing and their lack of belief, we would take this to be reason for retracting their articles. Their PWB, if revealed, will be treated as a mistake or a problem. However, the same is clearly not true for Sanjay and Rachel. ${ }^{9}$ Objections to Sanjay and Rachel's arguments will be submitted to journals as new potential publications, rather than sent as emails to editors requesting retractions. Recognition of this is part of what motivates the previously mentioned literature on the nature of philosophical commitment.

The difference between the two sets of cases is in the kind of claims being made. I understand a claim to be a token speech act: an uttered statement. A published claim is a statement written in an article, book, dissertation, etc.. The theory offered here is neutral about what type of speech act such claims represent. I suspect these claims are all assertions, despite being used to play distinct roles in inquiry. But the view on offer is compatible with the idea that advocacy role claims and evidential role claims are distinct types of speech acts. (Use of the term 'claim' facilitates this neutrality.)

Plakias' cases involve advocacy role claims. The authors publish them in order to advocate for a particular view or theory. The authors thereby provide new and interesting arguments for their views in order to take part in productive discourse and debate in philosophy. As Plakias puts it, they are providing potentially convincing arguments. Furthermore, they are positioning themselves as defenders of the theory they are advocating, who will respond if their claims are challenged. This allows them to engage in debate and disagreement which will be beneficial for their field. This kind of advocacy is an important part of productive inquiry. ${ }^{10}$

\footnotetext{
${ }^{9}$ As already discussed, Ben's behavior in malicious deceiver seems more controversial.

${ }^{10}$ Ben's case is again a bit complicated, as he stops defending the claim immediately upon publishing it. Still, I think the basic picture still fits: he is proposing and (temporarily) defending a theory in order to improve collective inquiry. The means by which it aims to advance inquiry is simply different: it is meant to help improve publication practices.
} 
I will not offer a definition or conceptual analysis of the advocacy role, but here is a characterization:

Advocacy Role Claims: Claims that aim (or function) to promote productive debate and disagreement.

This is a characterization in terms of what the claims do: they play the role of entries into debate. Such claims are meant to elicit disagreement in the form of objections and contrary claims from readers. They create a pro tanto obligation for the author to defend them. The resulting back and forth of objections and replies is helpful in the pursuit of knowledge and understanding. ${ }^{11}$ An author need not explicitly have this intention in order for the claims to have this function. A claim also need not achieve this aim in order to count as being an advocacy role claim.

Importantly, due to their function, advocacy role claims usually will not be immediately believed or taken on trust by the reader. Philosophers recognize the distinction between the two roles, as evidenced by our differing intuitions in the two kinds of cases. When making advocacy claims, authors expect their readers to recognize this, and to provide similarly motivated and supported counter-claims. These advocacy claims and counter-claims partially constitute debates which are important parts of productive inquiry. This explains the good consequences for inquiry we can expect in Sanjay and Rachel's cases.

A single published work may contain many claims made in the advocacy role. Often, the thesis of a paper will play the advocacy role. But advocacy role claims will rarely be limited to the thesis. An author may give elaborate arguments in which many of the premises are also advocacy role claims. Most often, however, at least some of the claims in a paper will instead play an evidential role.

Repentant (non)realist offers a useful example. Sanjay's defense of moral non-naturalism involves a variety of advocacy claims, including those that help elucidate the meaning of the theory, serve as important premises, or discuss important upshots (e.g., that the truth of moral non-naturalism is evidence for Platonism about mathematical objects). Any of these claims may be appropriately published without belief, because they play a role in advocating a view (or part of a view) in productive discourse and debate.

Sanjay is described as having a "compelling" response to many objections to non-naturalism, despite not believing non-naturalism. This leaves open whether he believes that the response works against the objections. He might not; rather, he might take some weaker attitude to the quality of the response. It might be that he recognizes that it seems compelling, but withholds judgment on how well it works, perhaps waiting to hear how his peers respond to it, or perhaps thinking there may be defeating considerations he has missed. Whether he believes the response works or not, he can permissibly publish it, as it can play an advocacy role. Regardless of his

\footnotetext{
${ }^{11}$ For support of the claim that such debate is beneficial for inquiry, see Mercier and Sperber (2011), De Cruz and De Smedt (2013), and Fleisher (2020).
} 
beliefs, he will not expect others to take his claims about its quality based on faith in his testimony. That is not the role his publishing the response plays in discourse. This kind of advocacy is clearly beneficial for philosophical inquiry. This explains why PWB is permissible in such cases.

Evidential role claims serve a different function than advocacy role claims. I will similarly characterize (but not define) them:

Evidential Role Claims: Claims that aim or function to increase the common stock of evidence available to inquirers.

We can remain reasonably neutral about the nature of the common stock of evidence. One plausible construal is: claims mutually accepted by a community of inquirers. On this view, an evidential role claim aims to add to what is mutually accepted by inquirers. But the above characterization is compatible with a variety of views about the nature of evidence possession. Still, it seems intuitive that inquirers should be in a position to justifiably believe claims in their common stock of evidence. Thus, unlike advocacy role claims, evidential role claims aim to justify readers' beliefs in them.

Consider a good case of published evidential role claims:

Well-read epistemologist: Amanika writes an overview article for an online encyclopedia about testimony. She does not claim that any particular theory about testimony is correct. She focuses on summarizing and explaining the available views. She reads broadly and carefully in the testimony literature, including all the papers that she makes claims about. On this basis, she justifiably believes all the claims in her paper.

Amanika publishes epistemically appropriate evidential role claims. She intends and expects that her claims will be believed by her readers, and added to their common evidence. (Note again, however, that the aim need be neither explicit nor achieved.) Furthermore, we can imagine that the overall picture of the field she offers is one that she justifiably believes. Even her thesis, then, is an evidential role claim. I think it is clear that, when making this kind of argument, it is only permissible for Amanika to publish claims she believes.

Evidential role claims are also important for productive inquiry. They allow information to be added to the common stock of evidence in a field. This provides an additional and important means for pursuing the goals of inquiry. Low epistemic standards for making such claims would lead to bad consequences: first to falsehoods entering the common evidence in the field, and subsequently to a loss of trust. Both outcomes degrade the ability of a field to accumulate and share evidence. Hence, it is important to maintain high epistemic standards, including that authors (justifiably) believe the evidential role claims they make. This is why Amanika's claims are intuitively permissible, and Chet, Linda, and Nelson's are impermissible.

In most published papers, I suspect that authors will employ both advocacy and evidential role claims. Their thesis and many supporting (and 
entailed) claims will be made in the advocacy role. Many other claims, however, will be made in the evidential role: they will provide evidence that readers can rely on. Sometimes, evidential role claims may only serve to bring some piece of common knowledge to salience. In other cases, some readers might find the information contained novel and add it to their own beliefs. In either case, a high, belief-involving epistemic standard will be appropriate.

While evidential role claims are governed by higher epistemic standards, I do not mean to suggest that advocacy role claims do not have their own norms and standards. Whether advocacy is permissible in a particular circumstance will depend on whether it will promote productive inquiry. The recent literature mentioned above, about the appropriate attitude toward philosophical views, offers some guidance on the norms for published advocacy claims. Such norms should be sensitive to considerations about what promotes healthy collective inquiry. That a particular theory is novel, plausible, or under-explored are all reasons to advocate for it.

\section{Conclusion}

Recognizing two roles for published claims allows us to explain the intuitions in all seven of the cases discussed. Plakias' cases are permissible instances of publishing without belief because the protagonists are making advocacy role claims. Fraudulent deceiver, negligent experimenter, and poorly-read ethicist involve impermissible PWB because their protagonists are making (unwarranted) evidential role claims. Meanwhile Amanika in well-read epistemologist is permissibly publishing evidential role claims because she justifiably believes them. Making this distinction provides a well-motivated way of explaining the differences in these cases. It offers an answer to the question of when it is permissible to publish without belief.

An important upshot of this theory is that it no longer requires a restriction to philosophy. There is every reason to expect that scientists can make the same distinction between advocacy and evidential role claims in their publishing. Plakias initially limited the discussion to philosophy due to a concern that publishing the results of empirical research without believing them would be clearly problematic. However, we are now in a position to distinguish between reporting empirical results and advocating for a theory: the former involves evidential role claims, and the latter involves advocacy role claims. This applies just as easily in biology as it does in philosophy. Thus, the resulting theory is much more widely applicable.

There may be other helpful distinctions and categories that can be added to this account, and the account may need to be tweaked. However, given what I have argued above, it seems appropriate to advocate for this version of the account. 
Publishing without (some) belief

\section{Acknowledgements}

For helpful discussion and feedback on this paper I would like to thank Austin Andrews, Casey O'Callaghan, Andy Egan, Megan Feeney, Branden Fitelson, Peter Van Elswyk, and two anonymous reviewers at this journal.

\section{References}

Barnett, Z. (2019). Philosophy without belief. Mind, 128(509), 109-138. doi: $10.1093 / \mathrm{mind} /$ fzw076

Carter, J. A. (2018). On Behalf of Controversial View Agnosticism. European Journal of Philosophy.

Christensen, D. (2009, September). Disagreement as Evidence: The Epistemology of Controversy. Philosophy Compass, 4(5), 756-767. doi: 10.1111/j.1747-9991.2009.00237.x

De Cruz, H., \& De Smedt, J. (2013). The value of epistemic disagreement in scientific practice: The case of homo Floresiensis. Studies in History and Philosophy of Science Part A, 44(2), 169-177. doi: 10.1016/j.shpsa.2013.02.002

DeRose, K. (2002). Assertion, Knowledge, and Context. Philosophical Review, 111(2), $167-203$.

DeRose, K. (2016). The appearance of ignorance: Knowledge, skepticism and context, (Vol. 2). Oxford: Oxford University Press.

Douven, I. (2006). Assertion, knowledge, and rational credibility. Philosophical Review, 115(4), 449-485. doi: 10.1215/00318108-2006-010

Fleisher, W. (2018). Rational endorsement. Philosophical Studies, 175(10), 2649-2675. doi: 10.1007/s11098-017-0976-4

Fleisher, W. (2019). Endorsement and assertion. Noûs, forthcoming. doi: $10.1111 /$ nous. 12315

Fleisher, W. (2020). How to endorse conciliationism. Synthese, forthcoming, 1-27. doi: 10.1007/s11229-020-02695-z

Frances, B. (2010). The reflective epistemic renegade. Philosophy and Phenomenological Research, 81(2), 419-463. doi: 10.1111/j.1933-1592.2010.00372.x

Frances, B. (2013). Philosophical renegades. In D. Christensen \& J. Lackey (Eds.), The Epistemology of Disagreement. Oxford University Press Oxford.

Frances, B. (2014). Disagreement. Cambridge: Polity Press.

Goldberg, S. (2013). Defending philosophy in the face of systematic disagreement. In D. Machuca (Ed.), Disagreement and skepticism (pp. 277-94). New York: Routledge.

Goldberg, S. (2015). Assertion. Oxford: Oxford University Press.

Goldman, A. I. (2001). Experts: Which ones should you trust? Philosophy and Phenomenological Research, 63(1), 85-110. doi: 10.2307/3071090

Kitcher, P. (1990). The division of cognitive labor. The Journal of Philosophy, 87(1), 5-22. doi: $10.2307 / 2026796$

Kvanvig, J. (2011). Norms of assertion. In J. Brown \& H. Cappelen (Eds.), Assertion: New philosophical essays (pp. 233-250). Oxford University Press.

Lackey, J. (2008). A Justificationist View of Disagreement's Epistemic Significance. In A. M. A. Haddock \& D. Pritchard (Eds.), Proceedings of the Xxii World Congress of Philosophy (pp. 145-154). Oxford University Press. 
Lindsay, J. A., Boghossian, P., \& Pluckrose, H. (2018). Academic Grievance Studies and the Corruption of Scholarship.

Mahon, J. E. (2016). The Definition of Lying and Deception. In E. N. Zalta (Ed.), The Stanford Encyclopedia of Philosophy (Winter 2016 ed.). Metaphysics Research Lab, Stanford University.

McKaughan, D. (2007). Toward a richer vocabulary for epistemic attitudes (Unpublished doctoral dissertation). University of Notre Dame.

Mercier, H., \& Sperber, D. (2011, April). Argumentation: Its adaptiveness and efficacy. Behavioral and Brain Sciences, 34(2), 94-111. doi: 10.1017/S0140525X10003031

Palmira, M. (2019). Inquiry and the Doxastic Attitudes. Synthese, forthcoming, 1-27.

Plakias, A. (2019). Publishing Without Belief. Analysis, forthcoming, 1-10. doi: 10.1093/analys/anz040

Strevens, M. (2003, February). The role of the priority rule in science. The Journal of Philosophy, 100(2), 55-79. doi: 10.5840/jphil2003100224

Weiner, M. (2005). Must We Know What We Say? Philosophical Review, 114(2), $227-251$.

Williamson, T. (1996). Knowing and asserting. Philosophical Review, 105(4), 489-523. doi: $10.2307 / 2998423$

Williamson, T. (2000). Knowledge and its limits. Oxford: Oxford University Press.

Zollman, K. J. S. (2010). The Epistemic Benefit of Transient Diversity. Erkenntnis, 72(1), 17-35. doi: 10.1007/s10670-009-9194-6 